\title{
Hybrid Supported Employment Approach for Persons with Intellectual Disabilities in India: Evidence Based Case Studies
}

\author{
Priyanka Chandrasekaran - Sreekanth Nair Thekkumkara • Anandhi Jothibalan • \\ Aarti Jagannathan 1 - Deepak Jayarajan $\cdot$ Shanivaram K. Reddy
}

Received: 31 May 2021 / Accepted: 3 September 2021 / Published online: 6 October 2021

(C) The Author(s), under exclusive licence to Springer Nature India Private Limited 2021

\begin{abstract}
Studies have reported that persons with developmental disabilities have the lowest rate of labor force participation, relative to other disabilities due to various factors. This paper presents two cases studies of persons with ID who were successfully provided a hybrid supported employment approach of 'train and place model' and 'place and train model' by the Psychiatric Rehabilitation Services (PRS) team. Conducted a retrospective file review highlighting the process of supported employment approach adapted for persons with ID. The ethical approval was obtained from the Institute Ethical Committee. The hybrid supported employment approach focuses on enhancing client's vocational potential and skills, prepare for
\end{abstract}

P. Chandrasekaran · S. N. Thekkumkara $(\bowtie)$

A. Jothibalan - A. Jagannathan - D. Jayarajan .

S. K. Reddy

National Institute of Mental Health and Neurosciences

(NIMHANS), Bengaluru 560029, India

e-mail: Priyanka.chandrasekaran@gamil.com

S. N. Thekkumkara

e-mail: sreekanthnairgck@gmail.com

A. Jothibalan

e-mail: j.anandhi_89@yahoo.com

A. Jagannathan

e-mail: jaganaarti@gmail.com

D. Jayarajan

e-mail: deepak.jayarajan@gmail.com

S. K. Reddy

e-mail: shanivaramreddyk@gmail.com job ready, find a suitable job placement. Further, the approach helped in improving the sense of independence self-esteem and quality of life of the clients. A hybrid supported employment approach could be an effective method in aiding persons with developmental disabilities in India seek, get, and keep jobs; it will also help them deal with unique challenges they face in the workplace as well as loss of or gaps in employment. Involvement of families in the intervention will help minimize negative expressed emotions and distress.

Keywords Hybrid supported employment .

Supported Employment · Case study · Rehabilitation . Disability

\section{Introduction}

Studies have shown that employment provides financial security and improves the wellbeing and quality of life of persons with psychiatric and Intellectual Disabilities (ID) [1]. Supported employment, with its focus on facilitating successful participation in integrated work settings, provides an alternative to the day care and sheltered workshop models [2]. A systematic review conducted to understand the effectiveness of supported employment approach showed that it increased the length of competitive employment in 
comparison to other vocational approaches such as sheltered employment for persons with mental illness. Further the review also showed improvement in job retention period [3]. A feasibility study on supported employment of Persons with Severe Mental Disorders (PwSMD)in India showed that out of 63 PwSMDs who were part of the study, $32(50.8 \%)$ were placed in competitive jobs, placement was actively attempted for $17(27.0 \%)$ and $7(11.1 \%)$ were referred for skill training. The study also reported that their disability scores reduced significantly and socio-occupational functioning significantly improved in those who were placed over a period of 6 months [4]. Studies have also reported the role of reasonable accommodation in sustaining employment for persons with disabilities $[4,5]$, Rangarajan et al., n.d.)

Studies have reported that persons with developmental disabilities have the lowest rate of labor force participation, relative to other disabilities [6]. Skill deficits in multiple areas and lack of prior work experience function as internal barriers for employment, and paucity of exclusive skill training centers and other logistic barriers are external barriers [7]. Other reasons for exclusion from employment are employers' unfavorable attitude and stigma towards persons with IDD [6]. Deficits in core skills such as social skills. attention, interpersonal skills were also found to hinder persons with ID in maintaining their employment [6]

Vocational skill training and vocational rehabilitation is one of the most important services provide by Psychiatric Rehabilitation Services (PRS) team. In PRS, persons with IDD attend self-sustaining programs such as green skills, candle making, bakery and cafeteria (Roses Café) section for day to day engagement under the supervision of instructors and team members, along with persons with mental illnesses $[8,9]$. As a transitional approach, the team refers its clients based on their skills and interest to other vocational training centers for upskilling and supported (vocational) education (train and place model) apart from liaising with corporates and institutions for on the job training (place and train model) in competitive employment spanning different roles such as data entry operator, office assistant, front office management, and electrical repairing. The process includes liaising with different employers, identifying potential persons for the employment, skill assessment and skill training, and placement in a competitive employment. Further, the process also includes collecting continuous evaluation and feedback from the clients and their employers to understand the progress and challenges $[4,10]$. There were only few studies discussing the effectiveness of supported employment approach for persons with Intellectual disability (ID). In this paper the authors conducted a retrospective file review highlighting the process of supported employment approach adapted for persons with ID. This retrospective file review was approved by the Institute Ethics Committee of NIMHANS Bengaluru, India, for the purpose of publication in a scientific journal.

\section{Methodology}

\section{Case 1}

Mr. A, was a 29-year-old male, with mild ID [score of 50 as per Vineland Social Maturity Scale(VSMS) and Binet Kamat Test (BKT)] and Complex Partial Seizure(CPS), from urban Bangalore. He belonged to the middle socio-economic status as per Kuppuswamy socio economic scale [11] and had completed his graduation in (B.Sc.) Animation. He was referred to PRS for vocational skill training and supported employment by the treating team of neurology after managing CPS. Mr. A stayed in Bangalore with his parents; his elder sister was married and lived abroad. His mother, who actively participated in the treatment and rehabilitation needs of the client, was the primary care-giver for the client. However, his father's involvement was minimal, and though he was critical towards the client for not being financially independent. Mr. A's father had his independent business in which he attempted to include Mr. A. However, due to the lack of interest shown by Mr. A and inability of the father to provide adequate on-the-job training, this plan did not succeed. Mr. A had attended numerous BPO based job interviews without success - the major issue reported was inadequate competency in necessary job specific skills. This resulted in reduced self-esteem and increased A's anxiety about employment. He had good communication skills and maintained cordial interpersonal relations with others. The multidisciplinary team in PRS evaluated the client and planned rehabilitation goals by discussing with client and family. The supported employment goals were, 
(1) To conduct vocational assessment (2) To provide skill training and upskilling. (3) To facilitate job placement, (4) To provide follow-up services, (5) to work with family to facilitate supported employment.

\section{Interventions}

\section{Vocational assessment}

The client was assessed on his vocational potential using the Vocational Potential Assessment Tool (VPA). VPA is a comprehensive tool to assess daily functioning, job related social and cognitive skills, job readiness, family and client related information [10]. The assessment revealed that he was competent in areas of self-care, commuting to work alone, maintaining good interpersonal relation with his supervisors and peers at the work place, and maintaining professional boundaries. Patient had moderate disturbance in managing financial aspects, and could do basic calculations only with the help of calculator. He found it difficult to comprehend multiple instructions simultaneously and would repeated ask questions on how to do the work which would annoy his employers. He would also make the mistakes at work due to his inability to comprehend the work. As part of the vocational assessment, feedback about his potential was provided to $\mathrm{Mr} \mathrm{A}$ and his family. Mr A was still determined to work in a BPO setting. His family, especially his father, had high expectations from him and wanted him to prove his ability to support himself even without their help. This pushed Mr A to find a 'favourable' white collared job to satisfy his expectations and their hopes. His strengths were persistence in applying for jobs a job, readiness for skill training; his limitations were lack of understanding of his current capacity, high expectations from self, and low self-esteem from repeated failure in maintaining a job.

\section{Skilling Training}

In order to achieve his aim to work in a BPO, the client was referred to a skill training center (NGO) located in Bangalore for engagement. He attended the training for a period of two months, during which the PRS team negotiated with the training center for reasonable accommodation in terms of single supervision, individual attention in training, and frequent breaks during training. Post completion of his training, the skill training center facilitated a few job interviews for the client in which he could not qualify due to inadequate computer skills. To help in reskilling, the client was asked to attend the computer section in PRS for training in using Microsoft excel, to help him in getting future jobs. Weekly feedback was collected from the instructor to understand A's progress in computer skilling. He was regular to the computer section, able to understand the instructions, required minimal supervision and, learnt spreadsheet management skills well.

\section{Job Placement}

Even post reskilling, as Mr A was not very proficient with data entry or computers, the rehabilitation team liaised with the hospitality industry for a suitable job opportunity for the client in the area of front desk operations. The team negotiated for on-the-job training and hand holding support, single manager and reasonable accommodation in work-timings for $\mathrm{Mr} \mathrm{A}$. Discussion with the client and family about disclosure of clients ID for obtaining job placement with reasonable accommodation was conducted. Post consent of client and family for disclosure, $\mathrm{Mr} \mathrm{A}$ attended the interview and secured the job as a person with disability. He qualified for the front desk job and his salary was fixed at $£ 8000$ per month. The client and his family were happy with the job. The nature of work involved attending to guests who arrived and guiding them to their rooms. The team was in regular contact with the manager of $\mathrm{Mr} \mathrm{A}$ to understand his performance and challenges. The employers were happy with client's work and they reported that the client was regular to work, was able to complete his task and client had no interpersonal issues at the workplace. He was regular till March 2020 (4 months), after which the hotel had to temporarily close due to the COVID19 pandemic and lockdown. The client was kept on the bench and assured of returning to his job after the pandemic. During this period, to keep him engaged, the PRS team suggested he enroll for an online course on Transmission Control Protocol (TCP) hosted on Coursera for further enhancement of skills, which he chose.

\section{Follow-up Services}

UDID was processed for the client based on the disability assessment conducted by the clinical 
psychology team of PRS. This helped him to get a bus pass which enabled him to travel within $100 \mathrm{~km}$ radius of Bangalore city and to his place of work. Regular tele-follow-ups were conducted with the client and his family to check on his mental health and progress at work; due the pandemic, tele-sessions also focused on helping him have a structure at home (via providing him an activity schedule) and keep himself engaged.

\section{Work with Family}

Both the parents were provided psychoeducation about the client's ID and his current capacity. Though his father was not ready to accept the client's disability and his unique needs initially, he seemed to accept the situation over time with psychoeducation and engagement. Sessions with him about how his negative expressed emotions such as being hostile and critical could affects the client's confidence levels and mental health was discussed. A's mother was overinvolved and protective about $\mathrm{Mr} \mathrm{A}$; in the family sessions, she was suggested to aid the client in making his own career decisions, instead of stopping him from working or making choices for him.

\section{Outcomes}

The hybrid supported employment approach helped to assess the client's vocational potential, mirror his work capability to himself and his family, train him to be job ready, find a suitable job, which the client continued for 4 months, placement, and upskill him. Intervention during the pandemic helped to develop a proper schedule for the client, and reduce expressed emotions from his father. Finding work helped the patient's father appreciate the patient more, and he expressed that the patient was using his time gainfully. Client also reported that his self-confidence and esteem improved after he was employed. The main challenge faced in this case was the outbreak of pandemic which put the client on the bench at workplace. This long duration of work interruption often caused anxiety in the client and his family about whether he would be gainfully employed in the future.

Case 2

Mr. S was a 21-year-old male, with mild ID (Intellectual Disability), educated up to 9 th std. He was referred to the PRS team for vocational training and placement. He belonged to the middle socio economic status according to Kuppuswamy socio economic scale [11]. The client lived with his parents in Bangalore. His elder sister was married and settled in Bangalore. His primary care-giver was his mother, who actively participated in the rehabilitation process. The multidisciplinary team of PRS evaluated the case and prepared the vocational rehabilitation plans based on the client's needs. The needs reported by the client in assessment were to be independent, engage in a meaningful employment, and experience better social inclusion. The goals planned based on the client's needs were.

(1) To conduct vocational Assessment, (2) To facilitate skill training, (3) To place him in a suitable job, (4) to provide follow-up services

\section{Interventions}

\section{(1) Vocational assessment}

As a first step of vocational assessment [10] was conducted to understand the vocational potential of the client. The assessment found that, the client had difficulty in sustaining conversations, was unable to ignore environmental distractions, and had poor interpersonal relationships. However, his strengths were that he had previous employment history as a data entry operator and had the ability to follow the instructions. Client had worked in an NGO for a period of 2 years and was paid a salary of $£ 10,000 /$ - for doing basic data entry and photocopying work. After two years, as he was proficient in the job, the NGO suggested he look for competitive job opportunities in the community, and vacate his position for other persons with disability who needed skilling and training.

Mr. S and his mother were briefed about his strengths and limitations and counseled about the job opportunities that the $\mathrm{S}$ was able to perform. It was discussed that the client would be suitable for simple backend manual jobs, which required less interpersonal interactions. 
Skill Training

Mr. S was referred to a center for skill training to enable him to become job-ready. The training was for six months and it was for a BPO based job and involved him learning the English language; feedback was collected from the trainers regarding the progress and challenges. As the mother of the client insisted that a data entry job would be suitable for her son, after successful completion of the course, the PRS team referred him to another center for training in data entry related skills.

\section{Job placement}

Post skill training, the team liaised with two organizations working in the space of BPO and data entry for job placement of the client. However the client was not successful in getting the job as the employers found him not suitably skilled for the job roles. Efforts were also made by the team to help him get his old job back as a data entry operator; however that was also not successful due to lack of vacancies.

Based on the feedback given by the employers that Mr S was not skilled enough to hold a BPO or a data entry job, the rehabilitation team networked with the hospitality industry for backend jobs. Mr. S attended a job interview, and was selected for a laundry assistant job. His job profile included folding the bed sheets after the laundry. The team discussed with the employers about providing reasonable accommodation at workplace including providing day-shift work, giving simple instructions and positive feedback for work done. Client's salary was $£ 8000$ per month. Feedback received from the employers was that he was regular to work and did his job well. He was regular till March 2020, after which the hotel had to close down in view of COVID-19 pandemic. The client was also kept on the bench and was assured of getting his job back after the pandemic. During this period, to keep him engaged, PRS provided him an activity schedule to follow at home and encouraged him to participate in the online PRS day-boarder activities.

\section{Follow-up Services}

Regular tele-follow-ups via email were exchanged with the client and his mother to check on his mental health and progress at work; especially during the pandemic online tele-sessions were held to help him have a structure at home (via providing him an activity schedule) and keep himself engaged.

\section{Outcomes}

As a result of the hybrid supported employment approach, the client's job-related skills improved; he started attending work regularly, sustained his job for 4 months, until the restrictions due to COVID 19 pandemic, he was able to have a sense of independence and procure things with his own money, and it also improved the self-esteem and quality of life.

\section{Discussion}

Employment is a critical felt need of persons and families of persons with various disabilities including developmental disability [12]. The Rights of Persons With Disabilities Act(RPWD), a right based legislation of 2016 and other legislations emphasize the need for ensuring reservation, skill training and employment for persons with developmental disabilities [5], In addition, as per the RPWD out of $4 \%$ of reservation for employment $1 \%$ is exclusively allocated for persons with various mental health spectrum conditions - including persons with developmental disorders - and those who have multiple disabilities. Further, there are private entrepreneurs who have also started adopting the concept of inclusion of persons with neurodiversity, including those with intellectual disability, in the workforce. In spite of these initiaves, the representation of persons with developmental disabilities in competitive employment is minimal [6].

There are different models established for persons with developmental disabilities such as day care/pre vocational training centres, sheltered workshop models [13]; however, these models do not provide adequate opportunities for persons with developmental disabilities to engage in competitive employment, and often, do not offer ways of earning a living wage. The current hybrid model of supported employment approach included skilling clients to be job ready while not in active employment and facilitating job placements when they expressed readiness has shown success, and encouraged persons with ID to work in 
mainstream community settings. A similar hybrid model of 'train and place 'and 'place and train' as depicted in this paper has shown to be efficacious in providing vocational services to persons with severe mental illness in France and Quebec [14]

Studies reports that employment helps in changing the status of the persons with disabilities across various domains such as reduced financial burden, improvement of quality of life and self-esteem, enhanced standard of living, alleviation of stigma in the community and reduced emotional burden with greater individual autonomy [4]. In addition, studies also shown that meaningful employment is associated with improvement of a range of skills including cognitive abilities, social skills, interpersonal skills and community integration $[15,16]$. The cases reported improvement in self-esteem, and qualitative life post supported employment intervention.

A multidisciplinary team is required for the assessment of vocational skills, skill training, and planning of vocational rehabilitation goals is essential during the process of supported employment [4] as illustrated in the two cases described. Studies also reports that an active role by the mental health professionals and integration of mental health services in the work places would enhance the quality of work and job retention in supported employment [17]. Collaboration and networking with potential employers and NGOs another important aspect in the process of supported employment for persons with developmental disabilities [4]. The role of various NGOs in skill training for persons with disabilities were recorded in India [13] and in the above illustrated cases, NGOs played a vital role in skill training and placement.

Follow-up services form an important part of helping the client sustain the employment. Concurrent feedback collected by the multidisciplinary team to understand the challenges and progress of the client in the work place and tele-follow-up sessions helped in both the clients maintaining their job and performing well till the advent of the pandemic. The principles of supported employment models discuss about the role of continuous support in sustaining employment [18]. Further, the team has negotiated for reasonable accommodation with the employers so that the work environment could be conducive for the clients. Studies discuss about the reasonable accommodation in the work places and its important(Rangarajan et al., n.d.)

The main challenge was the advent of the COVID19 pandemic which shifted both the clients to the bench in their workplace. The case studies depict the value of a hybrid supported employment approach for persons with developmental disabilities in overcoming unexpected changes in employment status. Engaging the clients at home and managing their anxiety about getting back to work post the pandemic was important in maintaining their mental health. However care needs to be taken in generalizing this model outside of NIMHANS, where mental health professionals are fewer in number and multidisciplinary teams for providing vocational rehabilitation are a luxury. In such a scenario, it is important to advocate for inclusion of this hybrid model as part of the Taluk or District Mental Health Programme (TMHP/DMHP) where the psychiatric social workers can be engaged in providing this service on at least one day in a week of their schedule.

A major limitation of this model is that it is resource intensive as it requires multidisciplinary team approach and requires active liaison between client and the employers. This may be available only in a few tertiary care centres and not in the community. It was also observed that it was effective because the severity of disability in both cases was mild-moderate. Vocational rehabilitation of clients with severe disability may require a different model itself which needs to be developed and tested. However, the strength of this paper is that it is one of the first to depict the effectiveness of Hybrid Supported Employment model for persons with IDD which could be a model to implement by other mental health professionals in the field.

\section{Conclusion}

The cases demonstrated the effectiveness of a hybrid model of employment for persons with IDD. The model helped in identifying the interests, skilling, upgrading the job related skills, find a suitable employment and retention of employment for clients with developmental disabilities. The findings also suggest that, the model could help in attaining financial independence and enhance the self-esteem of the clients. 
Acknowledgements Nil.

Funding Nil.

Declarations

Conflict of interest The authours declare that none of them have any conflict of interests.

Prior Presentation Nil.

\section{References}

1. Burns T, Catty J, Becker T, Drake RE, Fioritti A, Knapp M, Lauber C, Rössler W, Tomov T, van Busschbach J, White S, Wiersma D. The effectiveness of supported employment for people with severe mental illness: a randomised controlled trial. Lancet (London, England). 2007;370(9593):1146-52. https://doi.org/10.1016/S0140-6736(07)61516-5.

2. Michon H, Van Busschbach JT, Stant AD, Van Vugt MD, Van Weeghel J, Kroon H. Effectiveness of individual placement and support for people with severe mental illness in the Netherlands: A 30-month randomized controlled trial. Psychiatr Rehabil J. 2014;37(2):129-36. https://doi.org/10. 1037/prj0000061.

3. Kinoshita Y, Furukawa TA, Kinoshita K, Honyashiki M, Omori IM, Marshall M, Bond GR, Huxley P, Amano N, Kingdon D. Supported employment for adults with severe mental illness. Cochrane Database Syst Rev. 2013. https:// doi.org/10.1002/14651858.CD008297.pub2.

4. Jagannathan A, Harish N, Venkatalakshmi C, Kumar CN, Thirthallli J, Kumar D, Bhola P, Prasad MK, Thanapal S, Hareesh A, Jayarajan D, Govindan R, Chaturvedi SK. Supported employment programme for persons with severe mental disorders in India: A feasibility study. Int J Soc Psychiatry. 2020;66(6):607-13. https://doi.org/10.1177/ 0020764020918278.

5. Minsitry of Law and Justice. (2016). The Rights of Persons with disability Act, 2016. Government of India.

6. Khayatzadeh-Mahani A, Wittevrongel K, Nicholas DB, Zwicker JD. Prioritizing barriers and solutions to improve employment for persons with developmental disabilities. Disabil Rehabil. 2020;42(19):2696-706. https://doi.org/10. 1080/09638288.2019.1570356.

7. Thekkumkara SN, Jagannathan A, Sivakumar T. Pradhan Mantri Kaushal Vikas Yojana (PMKVY): Implications for Skills Training and Employment of Persons With Mental Illness. Indian J Psychol Med. 2021. https://doi.org/10. 1177/0253717621997180.

8. Roy A, Sivakumar T, Jayarajan D, Maithreyi NB, Balasubramanian M, Kalyanasundaram S, Thirthalli J. Ecofriendly holi colors: hospital based 'income generation activity' for persons with mental health challenges at a quaternary mental health care facility in India. J Psychosoc Rehabilit Mental Health. 2019. https://doi.org/10.1007/ s40737-019-00138-8.

9. Thekkumkara SN, Jagannathan A, Jadhav P, Durgoji SK, Muliyala KP, Angothu H, Reddi VSK. Family centric rehabilitation' for persons with mental illness in India: Conceptual framework using evidence-based case studies. Asian J Psychiatr. 2020;54: 102344. https://doi.org/10. 1016/j.ajp.2020.102344.

10. Harish N, Jagannathan A, Kumar CN, Thirthalli J, Chaturvedi SK, Kumar D, Bhola P, Prasad Muliyala K, Thanapal S, Radhakrishnan G, Angothu H, Jayarajan D. Development of vocational potential assessment tool and counseling module for persons with severe mental disorders. Asian J Psychiatr. 2020. https://doi.org/10.1016/j.ajp. 2019.101866.

11. Sharma R. Revised Kuppuswamy's Socioeconomic Status Scale: Explained and Updated. In INDIAN PEDIATRICS (Vol. 867) 2017. www.scaleupdate.weebly.com

12. Waghmare A, Sherine L, Sivakumar T, Kumar CN, Thirthalli J. Rehabilitation needs of chronic female inpatients attending day-care in a tertiary care psychiatric hospital. Indian J Psychol Med. 2016;38(1):36-41. https://doi.org/10. 4103/0253-7176.175104.

13. Roy A, Jayarajan D, Sivakumar T. Income Generation Programs for Persons with Mental Health Challenges: Practices from 13 Indian Mental Health Rehabilitation Centers. Indian J Psychol Med. 2020. https://doi.org/10. $1177 / 0253717620959759$.

14 De Pierrefeu I, Charbonneau C. Deux structures d'insertion professionnelle de format hybride pour personnes avec un trouble mental: les ESAT de transition de Messidor (France) et Accès-Cible SMT (Québec). Encephale. 2014. https:// doi.org/10.1016/j.encep.2014.04.003.

15. Ravilla S, Muliyala K, Channaveerachari N, Suresha K, Udupi A, Thirthalli J. Income Generation programs and realworld functioning of persons with schizophrenia: Experience from the thirthahalli cohort. In Indian Journal of Psychological Medicine (2019; Vol. 41, Issue 5, pp. 482-485). https://doi.org/10.4103/IJPSYM.IJPSYM_151_19

16. Srinivasan L, Tirupati S. Relationship between cognition and work functioning among patients with schizophrenia in an urban area of India. Psychiatr Serv. 2005. https://doi.org/ 10.1176/appi.ps.56.11.1423.

17. Higginbotham BJ, MacArthur S, Dart PC. 4-H Mentoring: Youth and Families with Promise-Adult Engagement and the Development of Strengths in Youth. J Prev Interv Community. 2010;38(3):229-43. https://doi.org/10.1080/ 10852352.2010.486300.

18. Drake RE, Bond GR, Becker DR. Individual Placement and Support. In Individual Placement and Support: An Evidence-Based Approach to Supported Employment. 2012. https://doi.org/10.1093/acprof:oso/9780199734016.001. 0001

19. Rangarajan S.. Muliyala KP, Jadhav P, Philip S, Angothu H, Thirthalli $\mathrm{J}$ (n.d.). Reasonable Accommodation at the Workplace for Professionals with Severe Mental Illness: A Qualitative Study of Needs. Indian Journal of Psychological Medicine. Retrieved May 24, 2021, from https://journals.sagepub.com/doi/pdf/https://doi.org/10.1177/ 0253717620939771

Publisher's Note Springer Nature remains neutral with regard to jurisdictional claims in published maps and institutional affiliations. 